\title{
The Management of a Mediation Organization According to the Italian Law
}

\section{Piera Pellegrinelli}

Università degli Studi di Bergamo, Bergamo, Italy.

Email: piera.pellegrinelli@unibg.it

Received September $24^{\text {th }}, 2012$; revised October $25^{\text {th }}, 2012$; accepted November $5^{\text {th }}, 2012$

\begin{abstract}
The article follows the aim to explain the management of a mediation organization according to the Italian law. Rules and regulations concerning mediation organizations are briefly and concisely outlined in item III, Legislative Decree No. 28 of 4 March 2010, which is the main measure. Italy has than introduced different rules which provide a better definition of the running of a mediation organization: Ministerial Decree No. 180 of 18 October 2010; Regulation of 4 November 2010; Ministerial Circular of 4 April 2011; Ministerial Circular of 13 June 2011; Ministerial Decree No. 145 of 6 July 2011; Ministerial Circular of 20 December 2011. The work analyzes the bodies involved in the mediation: the Ministry, the mediators and the parties.
\end{abstract}

Keywords: Mediation; Conciliation; Civil and Commercial Matters; Rules; Ministry; Mediators; Parties

\section{Introduction}

Article 60 of Law No. 69 of 18 June 2009 delegated power to the Italian government to issue one or more Legislative Decrees on mediation and conciliation in civil and commercial matters ${ }^{1}[1]$, on the basis of the directive criteria provided in Article 60 of the same Law [2,3], in order to conform Italian legislation to the principles established by the European Union.

Rules and regulations concerning mediation organizations are briefly and concisely outlined in item III, Legislative Decree No. 28 of 4 March 2010.

One of the fixed points, from which the regulation of mediation organizations originates, is a register ${ }^{2}$ [4]. In order to be entered in the register, mediation providers must apply to the Ministry of Justice (executive body whose duties are also register control and examination of the organization's reliability and efficiency ${ }^{3}$ [5]) and submit their code of ethics, as well as the rules of procedure containing charts for indemnity payment to the organizations and guarantees ${ }^{4}[6]$.

The formulation of specific technical rules concerning the "Creation of the register and its revision, registration suspension and removal of members, the introduction of

\footnotetext{
1"Someone cosiders it as one of the most 'subversive' of the recent reforms”.

" "Organizations shall be entered in the register".

3"Register is controlled by the Ministry of Justice, and also by the Ministry for economic development, in accordance with the section of paragraph 2 concerning how to deal with consumer matters”.
}

separate sections within the register to record cases which require special competences, including in consumer and international disputes, as well as the definition of the indemnity due to mediation organizations" is delegated, under Art. 16 of Legislative Decree 28/2010, to special decrees issued by the Ministry of Justice in agreement with the Ministry for Economic Development.

Before analyzing responsibility and obligations established by rules and regulations gradually introduced, it is relevant to mention which requirements a mediation organization must meet as a consequence of what Legislative Decree No. 28 of 4 March 2010 states.

Indeed, in Article 16 of Legislative Decree 28/2010 it is pointed out that "Public bodies or private entities with the required reliability and efficiency" are authorized to set up organizations which will manage the mediation process.

These requirements are certainly fulfilled by Bar Councils, which have the right ex lege to set up mediation organizations and to be entered in the register of the

\footnotetext{
4" Besides the application for registration, the Organization submits its rules of procedure and its code of ethics to the Ministry of Justice and shall communicate any subsequent change. In accordance with what established by this decree, the rules shall include computer procedures used by the organization; in this way it is possible to guarantee communication protection and respect of confidentiality of data. Charts concerning indemnities due to organizations set up by private bodies shall be enclosed to the rules of procedure and submitted for approval confidentiality of data, in accordance with Article 17. The Ministry of Justice considers the suitability of the rules in order to decide the Registration of an organization".
} 
Ministry of Justice "by means of simple application ${ }^{5}$ [7]”, but also by Councils of other professional orders, as regards matters within their competence, and by Chambers of Commerce, Industry, Crafts and Agriculture ${ }^{6}$ [8].

In truth, the explanatory report in Legislative Decree No. 28 of 4 March 2010 states that as far as Councils of professional orders and Chambers of Commerce are concerned, although the public law nature of these bodies offers guarantees of reliability and efficiency, the Registration of Organizations is subject to the authorization by the Ministry of Justice, which checks the fulfillment of the minimum requirements "which allow the organization to carry out the activity".

Besides these preliminary requirements, a set of rules, which provide a better definition of the running of a mediation organization, was introduced through subsequent regulations: Ministerial Decree No. 180 of 18 October 2010; Regulation of 4 November 2010; Ministerial Circular of 4 April 2011; Ministerial Circular of 13 June 2011; Ministerial Decree No. 145 of 6 July 2011; Ministerial Circular of 20 December 2011.

Given this set of rules, it is possible to identify, with reference to the bodies, a series of requirements and obligations towards the Ministry 1), the mediators themselves 2) and, of course, towards the parties which turn to them for mediation.

\section{Obligations of the Mediation Organization: Towards the Ministry}

\subsection{Registration}

Under Article 16 of Legislative Decree No. 28 of 4 March 2010 "the organizations must be entered in the Register".

Rules and regulations concerning the register are outlined in Article 3 of Ministerial Decree No. 180 of 18 October 2010, which institutes the register of the organi-

\footnotetext{
5“Bar Councils can set up organizations in every court, availing themselves of their staff and using venues placed at their disposal by the president of the court. Organizations are registered in courts by means of simple application, in accordance with criteria established by decrees referred to in Article 16.”

6 “ 1 . Councils of professional orders can set up special organizations, for matters within their competence and by previous authorization of the Ministry of Justice, availing themselves of their staff and using venues at their disposal. 2. Organizations described in paragraph 1 and organizations set up under article 2, paragraph 4 of law No. 580 of 29 December 1993 by Chambers of Commerce, Industry, Crafts and Agriculture are registered by means of simple application, in accordance with criteria established by decrees referred to in Article 16". For completeness reasons, the text of Article 2, paragraph 4 of Law No. 580 of 29 December 1993 (Reorganization of Chambers of Commerce, Industry, Crafts and Agriculture) is quoted: “Article 2 (Tasks and functions). 1 - 3 (Omissis); 4. In order to reach their goals, Chambers of Commerce promote, realize and manage structures and infrastructures of general economic interest at a local, regional and national level directly or through the contribution of other public or private bodies, in accordance with the laws of the Civil Code, for organizations or associations. 5-9 (Omissis)".
}

zations authorized to provide mediation service at the Ministry, within the human, financial and instrumental resources already present at the Department for justice affairs. Moreover it points out an organization of the register into parts and sections ${ }^{7}$ [9] and makes it compulsory for the person in charge to update it regularly and to manage it by computer ${ }^{8}$ for a fast elaboration of inserted data.

The responsibility for the register lay at first with the General Director of the Civil Justice Office, who was empowered to delegate the register-keeping only to a person with managerial qualification in the field of general direction.

As a consequence of Article 1 of Ministerial Decree No. 145 of 6 July $2011^{9}$ it is possible to delegate the register-keeping also to persons who have the qualification of judge and to have recourse to the general Inspectorate of the Ministry of Justice in order to perform the task of register control.

In truth, the reform simply authorizes, through an ad hoc legislative provision, a practice which has already established at the Ministry, considering that the so-called "judge in charge" has always dealt with the organization and coordination of the ministerial offices to which register control is entrusted.

These changes show the importance attached to the activity of control by the administration, as further tools were introduced to simplify the concrete examination of the activity of mediation during the preventive phase (that is on applying for registration, when correctness and fulfilment of the prescriptive requirements are checked) but also during the following phases (by checking the regular fulfilment of requirements and the respect of primary and secondary legislative provisions, as well as Mi-

\footnotetext{
7" The register is organized so as to include the following sections: part 1): public bodies; section A: list of mediators; section B: list of mediators expert in matters concerning consumer relationships; part 2): private entities; section A: list of mediators; section B: list of mediators experts in international matters; section C: list of mediators experts in matters concerning consumer relationships; section D: list of members, associates, managers, representatives of the organizations”.

${ }^{8}$ It seems useful to stress that the list of registered organizations can be found on the website www.giustizia.it, in the section "Tools", where these Organizations are ordered according to the number of registration. Moreover it is possible to search using parameters like town or municipal district where they work. It seems important to point out that on the list there are Organizations at a preliminary stage of registration as well (identified by means of a particular code) because they regularly submitted the application and after the deadline established to check the fulfilment of requirements on the part of the administration, the general direction registered them without checking and only because of the effect of implied assent. Anyway, the final registration will be reached only after checking the fulfilment of requirements.

${ }^{9}$ The provision has been filed: "Rules which modify the Decree of the Ministry of Justice No. 180 of 18 October 2010, about the determination of criteria and modalities for registration, the keeping of the Register of mediation organizations and the list of teachers for mediators, as well as approval of indemnities due to organizations, under article 16 of the Legislative Decree No. 28 of 4 March 2010”.
} 
nisterial Directives, on the part of bodies and mediators) [10].

In confirmation of what stated above, it seems useful to emphasize that the Ministerial Circular of 20 December 2011 [11] specifies the great importance attached to the so-called minimum quality standards concerning professionalism, efficiency and suitability of mediation organizations, which are considered as necessary requisites in order to manage to provide a proper mediation service. Furthermore the Ministerial Circular provides a first exemplification of the concrete examination procedure: Evaluation of failure to comply with communication rules imposed to the organization; check of the possible lack of minimum capital required, of minimum number of mediators, of biennial update for mediators, of timeliness of communications and timeliness in fixing the fist sessions, as well as examination of the respect of criteria for assignment of tasks.

The necessary criteria for registration, as well as their detailed description, are provided in Article 4 of Ministerial Decree No. 180 of 18 October 2010, which entrusts the examination of applicants' professionalism and efficiency to the person in charge. The criteria are the following:

1) Financial capacity and organizational capability of the applicant, as well as compatibility of the activity of mediation with the legal structure or membership purpose. The first requirement is met if applicants are able to prove that they own a capital which is not lower than the amount of money necessary to set up a limited company ${ }^{10}$. As far as the second requirement is concerned, applicants must certify that they are able to provide mediation service in at least two Italian regions or in at least two provinces of the same region. This can also take place by means of the agreements referred to in subsequent Article 7, paragraph 2, letter c), that is by means of agreements with other bodies which envisage the sharing of facilities, staff and mediators, provided that this is included in procedure Rules ${ }^{11}$ [12].

2) Availability, on the part of the applicant, of insurance covering any and all liabilities pertaining to the activity of mediation for a minimum of $€ 500,000.00$;

3) The requisites of good repute concerning members, associates, managers or representatives of the above-mentioned bodies, in line with those established in Article 13

\footnotetext{
${ }^{10}$ Under Article 2463 of the Civil Code, 2nd paragraph, n. 4) the amount of capital which is necessary to set up a limited company cannot be less than $€ 10,000$.

11،"The organization can include in the rules: [...] c) the chance of availing of structures, staff and mediators of other organizations with which it has reached an agreement to that end, also for the single mediation matters, as well as the chance of using the results of joint negotiations based on the agreement protocol between associations recognized under Article 137 of the Consumer Code and companies or their organizations and dealing with the same dispute”.
}

of Legislative Decree No. 58 of 21 February $1998^{12}$;

4) The administrative and accounting transparency of the entity, including the legal and business relationship between the organization and the body it might belong to as department, in order to prove to have the necessary financial and functional autonomy;

5) The guarantee of independence, impartiality and confidentiality during the mediation process, as well as the conformity of rules with the law, also as far as the legal relationship with mediators is concerned;

6) The number of mediators, at least five individuals, who declared themselves willing to perform the functions as mediators for the applicant;

7) The venues of the organization.

Besides the above-mentioned requisites, other requirements, concerning only mediators who belong to these organizations, must be met. The mediators must:

1) Have a level of education which corresponds to completed university studies of at least three years or be registered in a professional order or college;

2) Have a special training and a two-yearly training update. The previous formulation of Article 4, paragraph 3, letter b) of Ministerial Decree 180/2010 established, by means of the reference to Article 18 of the same rule, a basic training course lasting at least 50 hours and a two-yearly training update of a total duration of not less than 18 hours. These courses are theory and practical and deal with national, EC and international regulations concerning mediation and conciliation, with methodology of negotiation simplifying procedures, with techniques for dealing with situations of conflict and communication interactions, also with reference to mediation ordered by the judge. These courses are also about effectiveness of mediation and conciliation contract clauses, about structure, content and effects of the application for mediation

\footnotetext{
${ }^{12}$ The requirements of good repute were provided for by appropriate rules established by the Ministry of Economy and Finance, in agreement with Banca d'Italia and CONSOB. The rules were implemented by means of Ministerial Decree No. 468 of 11 November 1998. The requirements are: a) the absence of conditions of ineligibility or loss described in Article 2382 of the Civil Code, such as disqualification, failure or conviction to a punishment which implies the disqualification also temporarily, from public offices or the impossibility of working as manager; b) the absence of precautionary measures imposed by the legal authority under law No. 1423 of 27 December 1956 or under law No. 575 of 31 May 1965 and subsequent modifications and additions, except for the effects of reinstatement; c) the absence of irrevocable judgments, except for the effects of reinstatement: 1) prison sentence because of one of the crimes outlined by regulations about banking, financial, movable and insurance activity and by regulations concerning market and movable values, means of payment; 2) prison sentence because of one of the crimes described in section XI of book V of the Civil Code and in the king's decree No. 267 of 16 March 1942; 3) prison sentence for a minimum period of one year because of a crime against public administration, against public loyalty, against assets, against law and order, against public economy or because of a crime in tax matters; 4) prison sentence for a minimum period of two years for any crime committed with malice aforethought.
} 
and of conciliation agreements, and, finally, about the mediator's duties and responsibility [13].

The inappropriateness of these measures for training, stressed by many authors [14] in the legal field ${ }^{13}$ [15], led to a change of the regulation by means of Ministerial Decree No. 145 of 6 July $2011^{14}$ [16], in order to guarantee a proper and effective training for mediators.

Indeed the necessity of guaranteeing not only the mediator's theoretical education and professional training, but also a practical training whose aims are learning how other mediators manage the mediation process during its various phases and enriching the mediator's experience, even though indirectly, was recognized.

To that end the new text requires, besides the fulfilment of the requirements already established, the mediators' participation in twenty cases handled by the Registered bodies, which will be considered as assisted training.

The Circular for the interpretation of the corrective measures specifies that this "participation" must correspond to sheer assistance to the mediator with its activity, without providing further help to resolve the dispute.

The reason for this formulation lies in the necessary mutual trust between mediator and parties, who must be able to identify the mediator in charge of all phases of the procedure, even if a further subject (that is the trainee mediator) deals with them. For the same reason the participation of no more than one trainee mediator in each phase is suggested, but not explicitly regulated, and, therefore, it relies on the consideration on the part of the mediation organization, which should take into account a series of organizational aspects (concerning time and place) and reconcile this need with the features and work of the organization [10].

Even with reference to the twenty cases in which the trainee mediator must take part, some doubts concerning the way the twenty procedures should be counted were raised.

In particular, the regulation does not specify if "participation in the procedure" means the participation in a single phase or in the whole mediation process; moreover it is not stated explicitly if the so-called "non-active phases" (that is the cases in which, as a result of the mediation application of a particular party, a negative report is written because of the failure of the other party to participate) are considered as valid moments of assistance for the training.

\footnotetext{
${ }^{13}$ There are opposite opinions of people who think that the mediator's role should not be burdened with a heavy compulsory training, with reference to the task of taking part in disputes without the power to take compulsory decisions for the parties.

${ }^{14}$ “'2) Mediators shall be provided with a specific training and specific two-yearly update by training bodies under article 18 and shall take part during the two-yearly update as well as during the assisted training, in at least twenty mediation cases handled in registered organizations”.
}

By means of the interpretation provided by the Ministerial Circular of 20 December 2011, a solution to the above-mentioned doubts was provided. This text states that a preference must be given to the approach according to which "participation" also means presence during a single phase of the mediation procedure and recognizes that, despite the necessity of the trainee's participation in the active phase, because it is more consistent with the educational purpose of the regulation, "until the extrajudicial mediation reaches [...] a more frequent participation of the party which is invited to take part in the mediation procedure”, the presence of the trainee mediator to the writing of the negative report, written under Article 7, paragraph 5 of Ministerial Decree No. 180 of 18 October 2010, must be considered as valid.

Finally, it is important to mention that the regulation concerning training has been in force only since 26th August 2011 (that is since the date when the Ministerial Decree No. 145 of 6 July 2011 came into force) and, therefore, the two-year period within which the training must be completed begins at that date for already registered mediators, while it starts at the time of registration for those who registered in the relevant lists after 26th August 2011.

It has been remarked that during this initial phase of application of the mediation procedure, completing the training required could be difficult and that a postponement of the coming into force of the training would have been appropriate: it is clear, indeed, that during this phase the number of mediation practices started is not enough to guarantee all mediators the participation in twenty mediation cases, despite the expedient of considering the participation in non-active phases as valid for the final count.

3) Fulfill the requirements of good repute, as follows: 1) not to have been condemned because of a crime which was committed with malice aforethought, nor to imprisonment which has not been suspended yet; 2) not to have been disqualified from holding public offices temporarily or permanently; 3) not to have undergone safety or precautionary measures; 4) not to have undergone disciplinary sanctions different from warning.

4) Have the required documents which attest language skills for mediators who are going to register in the section of the register for experts in international matters.

\subsection{Application for Registration}

If public and private bodies and their respective organizations are able to guarantee the fulfilment of the abovementioned requirements, they can apply for Registration in the form outlined in the Regulation of 4 November 2010 provided by the General Director of the Ministry of Justice and according to the modality described in Article 5 of Ministerial Decree No. 180 of 18 October 2010. 
In particular it is possible to identify three application forms ${ }^{15}$.

1) A first application form for the registration of mediation organizations when the application is submitted by private entities. This form requires: the explicit indication of the deed of partnership of the body, from which it is possible to evict that the mediation activity is characteristic of the applying body ${ }^{16}$; the precise specification of the places where the mediation service will be provided, in conformity with what is stated in Article 4, paragraph 4, letter a) of Ministerial Decree No. 180 of 18 October 2010; the indication of the requisites established by regulations and concerning both organizations and mediators. For each registered mediator there is a form to complete and, if necessary, to complement with a selfcertification or appropriate documents (in case of mediators who are expert in international or consumer matters) as well as with the indication of the organizations for which the mediator is willing to work and the specification of not having declared to be willing to perform his/ her functions to more than five mediation organizations.

2) A second application form for the registration of mediation organizations when the application is submitted by public bodies and entities. The peculiarities of this form essentially depend on the differences, provided for in the rules, concerning the Chambers of Commerce and professional orders and imply the request only of the requisites therein outlined.

3) A third application form for the request of authorization to set up special organizations; this form corresponds to the one prepared to set up organizations on the part of professional orders which are different from the order of lawyers, as stated in Article 19 of Legislative Decree No. 28 of 4 March 2010.

The peculiarity of the forms lies in the indication of the matters within the competence of the professional order: this limits the number of disputes which can be entrusted to the organizations.

Besides the application form, organizations must submit the rules of procedure, the so-called evaluation form and charts for indemnity payment.

This is laid down not only in Article 5 of Ministerial Decree No. 180 of 18 October 2010, but also in the pre-

\footnotetext{
${ }^{15}$ In conformity with rules just referred to, which provide for various obligations of the Ministry, in particular for the appropriate communication of decisions concerning mediation, the form can be easily found on the website www.giustizia.it with the clarifying note prepared by the General Direction for Civil Justice of the Ministry of Justice, which briefly describes its purposes and content.

${ }^{16}$ This implies that in case the deed of partnership does not explicitly provide for mediation activity, it is necessary to complete it. This has two main functions: On one hand to guarantee the correct setting of the application as far as the indication of the activity is concerned; on the other hand to make the body understand that mediation service he/she is going to provide shall be considered as a central moment in the activity of the body.
}

vious Article 16 of Legislative Decree No. 28 of 4 March 2010, which regulates the technical features which characterize these documents.

\subsection{Rules of Procedure}

The above-mentioned measures ${ }^{17}$ [17] clarify that rules of procedure consist of a so-called necessary part, which contains elements that, according to law, cannot be excluded from the regulations, and a so-called optional part, which contains rules of procedure whose inclusion in the regulations relies on the consideration of the organization.

The necessary part includes: 1) "The indication of the place where the procedure takes place,18 [18] as well as the indication of the possibility of derogating from this with the consent of the parties, of the mediator and of the manager of the organization; 2) "Computer procedures the organization might use" which, if used, must be characterized by guarantees concerning communication protection and confidentiality of data, but they cannot constitute the only way to access the mediation procedure $^{19}$ [19]; 3) The subordination of the beginning of the procedure to the signing of the impartiality declaration ${ }^{20}$ [20] on the part of the appointed mediator; 4) The provision for delivery of the evaluation form; 5) The possibility, for the parties, of appointing the mediator jointly.

Besides the above-mentioned rules, through the changes made to Article 3 of Ministerial Decree No. 145 of 6 July 2011, two further rules of procedure were added and must be provided for in regulations as follows: 4) in case of compulsory mediation, the arranged meeting for mediation must take place even if the other party does not turn up or declares explicitly that it will not participate ${ }^{21}[21]$. In this case it is important that the inviting party takes

\footnotetext{
${ }^{17}$ The fact that the legislative decree implementing Article 60 of law of 18 June 2009 already dealt with some provisions delegated to subsequent ministerial decrees had already been remarked in Jurisprudence. Indeed before the coming into force of implementation rules, it was argued that if these rules did not include any provision about confidentiality of procedure, its length, mediators'duties, use of computer procedures and preparation of rules of procedure, these rules could and should find their source in the Legislative Decree No. 28 of 4 March 2010.

${ }^{18 \text { c }}$ The process is carried out without formalities at the venues of the mediation organization or at the place pointed out in the rules of procedure of the organization".

${ }^{19}$ "Rules shall include [...] computer procedures used by the organization; in this way it is possible to guarantee communication protection and respect of confidentiality of data" while in Article 7, 4th paragraph of Ministerial Decree No. 180 of 18 October 2010 it is established that "The rules cannot state that access to mediation is carried out only by computer". Criticism on this aspect was shown and the opportunity of introducing a brief regulation about computer procedures in requirements of rules of procedure was stressed, but it did not have effect.

20، The mediator has the duty of: a) writing, for each matter he is asked to deal with, a statement of impartiality using words established by the rules of procedure, as well as further requirements provided for by the same rules".
} 
part in the meeting with the mediator, that the failure of the called party to participate is recorded in the report, that the mediator writes a report on unsuccessful mediation and that, finally, this provision is included in the rules of procedure.

This modification simply gives legal expression to what had already been noticed through practice. The first clarifications about Ministerial Decree No. 180 of 18 October 2010 provided by the General Director of the Civil Justice Office considered as incorrect the introduction, in the rules of procedure, of a provision according to which the secretary of the organization could issue a written statement of procedure conclusion due to the failure of the called party to participate, without the inviting party's effective turning up before the mediator in a summons session $^{22}$.

This is the result of the fact that mediation has been provided for as a condition for the admissibility of civil proceedings, which implies that the procedure must take place concretely and that a negative report must be written by the only subject (the mediator) authorized to check that the called party did not turn up [22]; (vii) the provision for predetermined and binding criteria for the entrustment of the activity of mediation ${ }^{23}$ [23].

At the discretion of the organization, a series of rules of procedure, which were already pointed out in the Ministerial Decree No. 180 of 18 October 2010, can be included, such as: 1) the provision for personal appearance before the mediator. It is not really clear what the legislator meant with this provision: on one hand it is thought that it may point out to the power of the organization to entrust appearance before the mediator only to the personal party, without the involvement of a defence lawyer; on the other hand, and maybe more correctly, a literal interpretation is provided and it seems that the provision allows the mediator to hold separate sessions for each party, as in this way he can reach a better under-

\footnotetext{
${ }^{21_{\text {“In }} \text { cases provided for in Article 5, 1st paragraph of the Legislative }}$ Decree, the mediator meets the applying party even in case of failure of the called party to participate in the session, and the secretariat of the organization can issue a certificate of procedure conclusion only when the report of failure of the called party to participate and of failure to reach an agreement is written by the mediator under article 11, 4th paragraph of the legislative decree".

${ }^{22}$ This occurred during the first applications of the procedure also to solve a damaging situation concerning the applying party: the failure of the called party to participate implied that the applying party had to pay not only fees for the start of the procedure, but also subsequent fees and this just to get a report on unsuccessful mediation. In order to avoid this expensive disadvantage, some organizations agreed that in case the counterparty did not want to participate, the mediation attempt could be considered carried out when application was submitted and fees to start the procedure were paid, and that in this case the mediation report could be written without having to go before the mediator and, therefore, the applying party would not have to pay further fees.

23،"Binding criteria for the assignment of mediation matters which are preconceived and compliant with the professional competence of the appointed mediator, implied also by the type of university degree he/she has".
}

standing of the interests of the parties he has to reconcile $^{24}[24]$.

\subsection{The Evaluation Form}

In accordance with Ministerial Decree No. 180 of 18 October 2010, rules of procedure must also contain the form for evaluation of the mediation service ${ }^{25}$ [25].

An empty copy of the evaluation form employed by the organization must be enclosed to the regulations. The modalities for its submission to each party using mediation must be explained as well.

To that end, regulations must provide indications of the way to fill in the form, to sign it, to provide the necessary information and to send it by computer to the person in charge, so that receipt can be ensured.

By way of an example, it seems useful to stress that regulations usually provide for direct delivery of the form to the mediator, who deposits it in the organization's secretariat, which must deliver it by computer to the person in charge of the register of the organizations. However in some cases the mediator directly burdens the parties with the delivery of the form to the Ministry of Justice.

\subsection{Charts for Indemnity Zayment}

Charts for indemnity payment correspond to the schematization of the amounts charged to the parties for the use of mediation service provided by the organizations [26] and must be enclosed to the rules of procedure, as this is a provision included not only in Ministerial Decree No. 180 of 18 October $2010^{26}$ [27], but also in Legislative Decree No. 28 of 4 March $2010^{27}$ [28].

The subject of indemnity, immediately associated with the topic of costs, has always been important in rules and regulations governing mediation. Article 17 of Legislative Decree No. 28 of 4 March 2010 points out the reductions and tax exemptions from which the parties using mediation can benefit and describes the effects of compulsory mediation on $\operatorname{costs}^{28}$ [29].

A complete formulation of rules and regulations is provided in Ministerial Decree No. 180 of 18 October 2010, which was subsequently modified by the Ministe-

\footnotetext{
${ }^{24}$ Moreover, the chance of separate sessions is explicitly included: “As far as statements and information acquired during separate sessions are concerned and unless agreed by the party in question, the mediator has the duty of confidentiality towards the other parties”.

${ }^{25}$ "Rules shall in any case state: [...] that, at the end of the mediation process, each party is given an appropriate form for the evaluation of the service provided; the empty copy of the form shall be enclosed to the rules and a copy of the form with the signature of the party and its personal details shall be delivered by computer to the person in charge, using methods which guarantee its receipt”.

${ }^{26}$ “To the question is, in any case, the rules of procedure attached with [...] the list of the expenses set out with the criteria in the article".

${ }^{27}$ "Charts concerning indemnities due to organizations set up by private bodies shall be enclosed to the rules”.
} 
rial Decree No. 145 of 6 July 2011, as a consequence of the objections raised by the best jurisprudence authors about procedure costs and in the perspective of the enhancement of organizations which reach a resolution of their disputes more easily.

From the first formulation, indemnities include: 1 ) fees for the mediation procedure start and 2) mediation fees.

The first ones are the sums that the applying party must pay when it starts mediation, each corresponding to $€ 40.00$. These sums correspond to the minimum amount which makes possible the receipt of the application, the vision on the part of the secretariat, the activity of Registration and fascicle arrangement, as well as initial com-

28،1. Implementation of Article 60, paragraph 3, letter o) of Law No. 69 of 18 June 2009 imply that tax relief provided for in the same article, paragraphs 2 and 3, and by article 20, is part of the purposes of the Ministry of Justice which can be financed by means of a part of money received by the "Fondo Unico di Giustizia" and assigned to the said Ministry, under paragraph 7 of Article 2, letter b) of decree law No. 143 of 16 September 2008, converted with modifications by Law No. 181 of 13 November 2008, and under paragraphs 3 and 4 of Article 7 of Decree No. 127.2 of 30 July 2009 of the Ministry of Economy and Finance. All acts, documents and measures concerning mediation process are exempt from tax and from any cost. 3. The report concerning the agreement is exempt of register fee within the limit value of $€$ 50,000 , otherwise the fee corresponds to the amount in excess. 4 . The Decree referred to in Article 16, paragraph 2 lays down: a) the minimum and maximum indemnity due to public organizations, the calculation method and the modalities for al location among parties; b) criteria for approval of indemnity charts proposed by private entities; c) maximum increase of due indemnities, which cannot be over twentyfive percent, in case of successful mediation; d) minimum reduction of due indemnities in case the mediation is a condition for admissibility to court proceedings, under Article 5, paragraph 1.5 . When mediation is a condition for admissibility of application under Article 5, paragraph 1, no indemnity is due to the organization by the party which fulfils requirements for admission to defence provided and paid by the State, under Article 76 of the text of regulations concerning justice costs referred to in the Decree of the President of the Republic No. 115 of 30 May 2002. To that end the party shall submit the written statement replacing the affidavit to the organization, which can be authenticated by the mediator himself/herself and shall provide necessary documents to prove the truthfulness of what declared, if the organization requires it otherwise it will not be admitted. 6 . The Ministry of Justice carries out, within its institutional activities, monitoring of mediations concerning subjects exempt from payment of mediation indemnity. The results of the monitoring will be used to establish the indemnity due to public bodies as referred to in the decree, Article 16, paragraph 2, so as to cover the costs of services provided to subjects who are entitled to exemption. 7. The amount of indemnity can be reconsidered every three years in relation to the variation, checked by the National Institute of Statistics, of the consumer price index for families of employees and clerks, which characterized the previous three-year period. 8. The expense deriving from provisions in paragraphs 2 and 3, estimated $€ 5.9$ million for 2010 and $€ 7.018$ million starting from 2011 is covered through corresponding reduction of the amount belonging to the "Fondo unico di giustizia" referred to in Artile 2, paragraph 7, letter b) of the Decree Law No. 143 of 16 September 2008, converted, with modifications, by Law No. 181 of 13 November 2008 which, to that end, is still acquired at the definition of the Budget. 9. The Ministry of Economy and Finance carries out the monitoring of obligations established in paragraphs 2 and 3 . In case of changes compared to estimate provided in paragraph 8 , the further amount of money which is necessary to cover the further expense burdening on the sum of the "Fondo Unico di Giustizia” referred to in paragraph 8, is still acquired at the definition of the Budget”. munication.

Besides the payment of the fixed sum, it is provided for the payment, charged to each party, of a sum which varies according to the value of the dispute ${ }^{29}$, susceptible of increase or reduction according to the nature of mediation required or to the success or failure of mediation.

Ministerial Decree No. 145 of 6 July 2011 has the purpose on one hand of reducing mediation costs, and on the other hand of avoiding that the applying party is burdened with the whole costs in case of failure of the other party to participate ${ }^{30}$.

As far as increases or reductions are concerned, the sum belonging to a particular value bracket can vary because of:

-A provision for an increase up to a fifth due to the particular importance, complexity or difficulty of the case;

-A provision for a compulsory application of an increase up to a fourth, in case of successful mediation ${ }^{31}$;

-A provision for a compulsory raise of a fifth if the mediator draws up a proposal by joint request of the parties involved. This aspect, which was not modified by Ministerial Decree 145/2011, emphasizes, once more, one of the main aims of the decree, that is reaching an extra-judicial resoolution of disputes, which does not rely on a model oriented against the opposing party, but which is instead a synthesis of the different claims, according to the deflationary logic of the judicial contentious procedure [30];

\footnotetext{
${ }^{29}$ Mediation expenses are reckoned on the basis of value brackets shown in chart A enclosed to Ministerial Decree No. 180 of 18 October 2010, which establishes the following amounts: for disputes with a value up to $€ 1000.00$ a sum of $€ 65.00$ shall be paid; for disputes with a value between $€ 1001.00$ and $€ 5000.00$ a sum of $€ 130.00$ shall be paid; for disputes with a value between $€ 5001.00$ and $€ 10000.00$ a sum of $€$ 240.00 shall be paid; for disputes with a value between $€ 10,001.00$ and $€ 25000.00$ a sum of $€ 360.00$ shall be paid; for disputes with a value between $€ 25,001.00$ and $€ 50000.00$ a sum of $€ 600.00$ shall be paid; for disputes with a value between $€ 50,001.00$ and $€ 250,000.00$ a sum of $€$ 1000.00 shall be paid; for disputes with a value between $€ 250,001.00$ and $€ 500,000.00$ a sum of $€ 2000.00$ shall be paid; for disputes with a value between $€ 500,001.00$ and $€ 2,500,000.00$ a sum of $€ 3800.00$ shall be paid; for disputes with a value between $€ 2,500,001.00$ and $€$ $5,000,000.00$ a sum of $€ 5200.00$ shall be paid; for disputes with a value over $€ 5,000,000.00$ a sum of $€ 9200.00$ shall be paid.

${ }^{30}$ It is worth mentioning that European legislation, whose implementation has led to the regulation of mediation in our laws, has always supported the aspect of gratuitousness or, at least, the acceptable onerousness of alternative dispute resolution procedures; on order not to forget possible unconstitutional profiles which can derive from subordination of access to justice to the onerous attempt to reach agreement before the mediator. The Constitutional Court No. 67 of 29 November 1967 denies the possibility of subordinating the access to justice to the payment of a sum of money, and allows the subordination of the process only to judiciary fees.

${ }^{31}$ On this aspect a modification was made through Ministerial Decree No. 145 of 6 July 2011, which raised the amount of the premium (from "one fifth" to "one fourth" of the initial amount) due to the organization in case of successful mediation. This seems to be in opposition with the objective of cost reduction which led to the reform, but it benefits bodies which are able to reach successful mediation.
} 
-In case of mediation concerning compulsory subjects, a provision for a compulsory reduction of one third for disputes whose value belongs to one of the first six brackets (that is up to $€ 250,000.00$ ), while reduction will correspond to a half for the other value brackets.

This provision further reduces the amount to be paid for compulsory mediation compared to pre-existing rules and regulations, which provided for a single reduction, corresponding to a third of the due indemnity, for all reference brackets $^{32}$ [31];

-The provision for a reduction up to $€ 40.00$ for disputes belonging to the first value bracket or up to $€ 50.00$ for the others, in case of failure of the called party to participate in the procedure.

Besides the so reckoned amounts, actual and documented expenses borne by the organization for each aspect of mediation can be charged to the parties [32]. Under no circumstances, instead, the payment of further sums assignable to the mediator's fee shall be requested, because, in accordance with the explicit prescriptive provision, this is already included in the so-called mediation fees paid according to the established criteria. This applies even in case: of change of mediator from one session to the other one, of appointment of a board of mediators or in case of increase in the number of sessions which take place in the presence of the mediator [33].

At the discretion of organizations, it is possible to derogate from the minimum sum established for each reference value bracket [34].

As far as assessment of the dispute value is concerned, there is an explicit reference to the laws of Code of Civil Procedure and, therefore, it must be reckoned in accordance with Article 10 and following articles of Code of Civil Procedure.

The organization is empowered to decide at its discretion the value of the dispute in case of indeterminate, indeterminable value or when the parties disagree about its estimate.

As far as this is concerned, it was remarked that this right allows the organizations to evade the ordinary criteria for assessment of dispute value, as they have great discretionary powers and could, therefore, increase their revenue [35].

Limits to this discretionary power were set by means of the reform carried through by Ministerial Decree No. 145 of 6 July 2011, which introduced two substantial limitations: on one hand it established the maximum value assignable to the dispute on the part of the organzation,

\footnotetext{
32،"In paragraph 4, letter d) is replaced with the following text: "amounts described in Article 5, paragraph 1 of Legislative Decree, shall be reduced of one third in the first six brackets, and of a half for the other brackets, except for the reduction provided for in letter e) of this paragraph, and no other raise will be applied among those provided for by this article except for the raise provided for by letter b) of this paragraph"; the previous text simply stated: "Shall be reduced of one third, in the matters outlined in article 5, paragraph 1 of Legislative Decree”.
}

which corresponds to $€ 250,000.00$ and, on the other hand, it introduced a sort of safeguard clause which states that if at the end of mediation procedure the value of the dispute is different from the sum initially established, the amount of indemnity to pay depends on the reference value bracket $^{33}$ [36].

In case of non-payment, regulations do not explicitly provide neither for the possibility of suspending the procedure, nor for the possibility of refusing to carry out the mediation attempt.

It is true, however, that some jurisprudence authors [35] links this case to the "justified reason" which, as stated in Ministerial Decree No. 180 of 18 October 2010, allows the organization not to carry out mediation ${ }^{34}$ [37].

The possibility of refusing, which is abstractly admissible in cases where mediation is not compulsory, becomes feasible with difficulty in cases in which the mediation process is a condition of admissibility: compulsory mediation could unlawfully disadvantage the subject who does not pay indemnity and jeopardize the protection of a right guaranteed by the Constitution.

On the basis of the same principle, the legislator established that who is in a condition to receive legal representation paid by the State [38], does not have to pay any indemnity to the organization in order to start the mediation process in compulsory matters.

The application for the registration of a mediation organization, accompanied by all documents established by the regulations, must be sent to the Ministry using methods which guarantee its receipt.

The moment when the application is received is particularly important, because the forty-day period established by the legislator, within which the registration procedure must be completed, starts from that date ${ }^{35}$.

Rules state that after the deadline the organization is entered in the register all the same, although the person in charge has not checked that requirements are met and has not completed the registration.

Indeed, through this provision, rules and regulations about implied assent, described in law No. 241 of $7 \mathrm{Au}-$ gust $1990^{36}$ [39], are brought about. The subsequent

\footnotetext{
33، Paragraph 8 [of article 16, Ministerial Decree No. 180 of 18 October 2010] is replaced by the following text: "if the value is undetermined, or cannot be determined or there is a great divergence between the parties about its estimate, the organization decides the reference value up to the limit of $€ 250,000$ and it communicates this value to the parties. In any case, if at the end of the mediation process the value is different, the amount of due indemnity corresponds to the one provided in the reference bracket”.

34، After registration, organization and appointed mediator cannot refuse to provide mediation service, unless for good reasons".

${ }^{35}$ Article 5, 3rd paragraph, Ministerial Decree No. 180 of 18 October 2010, where it is provided for the possibility of suspension of the deadline in case the Person in charge needs supplements to the application or respective attachments. In this case, from the moment when supplementary documents are received by the Ministry, a twenty-day term is established.
} 
rules $^{37}$ clarified that if on one hand rules and regulations about implied assent cannot be brought about also in average conciliation, on the other hand, also as a consequence of the possibility of founding the application on self-certification, not just of the act of filing an application, the effects are the same as those of implied assent: there must be, therefore, a perfect correspondence between declarations and reality and a perfect fulfilment of requirements established by law ${ }^{38}$ [40].

Moreover administration is always empowered to proceed to the revocation of the act if, after its coming into force (and therefore even in case of implied assent), new facts occur and cause the act not to be effective any longer. People in charge to supervise organizations are entitled to check, at a later time, the lack of requisites imposed, their failure or the conflict between rules and primary or secondary laws, as well as the conflict between rules and primary laws or regulations.

\subsection{Obligations after Registration}

Through registration, each Organization is assigned a number, which identifies it unequivocally and constitutes its identification element.

Indeed, the first obligation which derives from Registration corresponds to the duty of providing this number in all acts, communications and advertising carried out in the forms allowed by law [41].

Besides this obligation, there is a series of duties which are indissolubly linked to the regular fulfilment, on the part of the organizations, of the requirements checked on

\footnotetext{
${ }^{36}$ It's particularly relevant as far as this aspect is concerned: "If the process must start after request, that is it must be formally started, public administration has the duty of ending it by means of an explicit provision" but also article 20: "Except for application of article 19, in procedures linked to the request of the party for administrative provisions, the lack of answer on the part of administration is equivalent to a provision for granting a request, without the necessity of further requests or warnings if the administration itself does not communicate to the party in question, as outlined in article 2, paragraphs 2 or 3, a measure of denial, under paragraph 2".

${ }^{37}$ Circular of 13 June 2011 of the General Director of Civil JusticeActivity of keeping the register of mediation organizations and the list of entities providing training. Indications about applicability of rules concerning implied assent.

38، 1 . As outlined in Articles 19 and 20, enclosed to denunciation or application the party in question shall provide a written statement certifying the fulfilment of requirements established by law. In case of mendacious statements or false declarations the setting up of the activity and its effects for law or the act of indemnity provided for by the same articles are not allowed, and the declaring party is punished with the sanction outlined in Article 483 of the Criminal Code, except for the case in which the fact is more serious. 2. Sanctions provided for when mediation activity is carried out without authorization of administration or in a different way are applied even towards those who start providing mediation service under articles 19 and 20 without fulfilling requirements or in contrast with laws in force. 2-bis. Assignment of tasks of prevention, control and supervision on activities subordinated to authorization on the part of public administration provided for by laws in force is still valid, even if mediation activity started under articles 19 and 20”.
}

applying.

In this perspective, each change in requisites, data and lists provided for the registration, including those concerning the fulfilment of the obligation of training update for mediators [42], must be immediately communicated to the keeper of the register.

Indeed, if new facts occur or are remarked and if before the registration the organization would not have been allowed to be entered in the register because of these facts, measures like suspension or removal from the register may be taken by the keeper of the register.

Likewise suspension or removal from the register can be decided in case of repeated violation of the mediator's obligations.

Besides these first situations, Article 10 of Ministerial Decree No. 180 of 18 October 2010 describes a case which leads ex lege to the removal from the register: having carried out less than ten mediation procedures within two years.

Even to that end, the supervision of the keeper of the register is very important: a decisive contribution is provided by the General Direction of Statistics of the Ministry of Justice, thanks to which the keeper of the register can monitor mediation procedures carried out by the single organizations.

This monitoring activity, at first established in order to check the financial availability of the State for the tax credit awarded to whom used mediation successfully or in order to cover expenses for the activity carried out for subjects free from indemnity payment [43], concerns not only the numerical flow of participations, but also pieces of information described in procedures concerning outcomes, matters considered and applying subjects.

The General Direction of the Ministry of Justice recommends a profitable participation on the part of the Organizations in this kind of activity, because the failure to take part actively in the monitoring may be considered as indicative of inactivity and lead to the suspension or removal from the register.

If necessary, through a special circular, the General Direction of Statistics of the Ministry of Justice provided the "monthly form" for the recording of mediation flows, where the procedures carried out by the Organization are classified according to the reference month, and the "mediation form", which contains specific and summarizing information about each procedure completed in the reference month. These forms must deal with monthly activity of each organization and must be reach the General Direction of the Ministry of Justice by 5th of the following month.

The possibility of suspension or removal of the Organization from the register is not so remote; therefore rules of procedure must provide a specific set of rules concerning the effects of suspension or removal from the regis- 
ter on procedures in progress [44]. Indeed, if an organization is removed from the register, it will not be allowed to enter the register again for a year from the date of the taken measure [45].

Finally, it is relevant to mention that preservation of requisites implies preservation of the effects that law acknowledges to procedure: the validity of the report as document of execution $^{39}$ [46] and the validity of the procedure for admissibility of court proceedings [47].

If parties turn to a non-authorized organization or to a suspended or removed organization, the report written by their mediator will not have the effects acknowledged to reports written by regularly registered Organizations.

\section{Obligations of the Mediation Organization: Towards the Parties}

Among aspects explicitly regulated by law there is the relationship between parties and mediation Organization, that is the relationship from which procedures to carry out average conciliation, in the strict sense of the word, before the mediator start off.

\subsection{Application for Mediation}

Parties which want to use mediation must submit a specific application to one of the registered organizations ${ }^{40}$.

There are no formal obligations, on condition that all data requested in the regulations are included in the application, so that the Organization, the parties, the object and the reasons for the request can be correctly identified $^{41}$ [48].

To that end all Organizations so far registered filed the empty copy of their application form, which shall be

\footnotetext{
39،1. The report on successful mediation, whose content is not against law and order or mandatory rules, is validated at the request of the party and through the check of formal regularity, by means of a decree of the president of the court which is located in the same district as the venues of the organization. In across-the-border disputes outlined in Article 2 of the Directive 2008/52/CE of the European Parliament and Council, of 21 May 2008, the report is validated by the president of the court in whose district the agreement must take place. 2. The report referred to in paragraph 1 constitutes the executive title for compulsory acquisition for enforcement in the specific form and for judiciary mortgage”.

${ }^{40}$ The list of registered organizations can be found on the website: www.giustizia.it, in the section "Tools", where these Organizations are ordered according to the number of registration. It's also possible to search an organization using parameters like town or municipal district where they work. It seems important to point out that on the list there are organizations at a preliminary stage of registration as well (identified by means of a particular code) because they regularly submitted the application and after the deadline established to check the fulfilment of requirements on the part of the administration, the general direction registered them without checking and only because of the effect of implied assent. Anyway, the final registration will be reached only after checking the fulfilment of requirements.

${ }^{41}$ The 1st paragraph states that "Application for mediation concerning disputes outlined in article 2 is submitted by means of delivery of an application to an organization [...]". The 2nd paragraph "The application shall point out the organization, the parties, the object and reasons for the request".
}

filled in with the data requested by the current regulations and by further regulations included in their own rules of procedure.

The choice of the Organization for application is entrusted to the first party which commits itself to start the mediation procedure. Indeed there are no rules for territorial competence which bind to start the procedure in a particular place. The only provision for this aspect concerns the place where the first and the other sessions before the mediator shall take place when the process has already started. The decree of implementation and the rules state that in rules of procedure of each Organization the place where sessions will take place must be explicitly pointed out and that the place can be changed only by previous agreement between the parties ${ }^{42}$ [49].

The delivery of the application, which can be carried out by mail or by hand to the secretariat of the Organization, constitutes a fundamental moment to establish the time of application ${ }^{43}$ [50].

This has two aims: on one hand to let the party define which organization will provide mediation service in case of delivery of more than one application to as many mediation Organizations. The criterion, in this case, is the following: the first Organization to which the application was delivered, deals with the dispute. On the other hand the aim is to set the deadline within which the procedure must be completed by the Organization ${ }^{44}$ [51].

To that end, on receiving the application, the secretariat of the Organization records the communication, assigns a progressive number to it and writes not only this number, but also the identifying data of the parties, of the object and of the assigned mediator in a particular register $^{45}$ [35].

Afterwards, the overall duration of the procedure and its outcome will be written near these data [52].

\subsection{The Procedure File}

When a party applies for mediation, the Organization

\footnotetext{
${ }^{42}$ “The mediation process takes place without formalities in the venues of the organization or at the place pointed out in the rules of procedure of the organization".

43،"In case of more applications concerning the same dispute, mediation is carried out before the organization to which the first application was submitted. In order to establish the time within which application must be completed, importance is attached to the date in which the first application was received".

${ }^{44}$ There is someone who thinks that the moment of pending suit of the application should coincide with the moment when the mediation proposal is communicated to the party called to take part to the procedure. ${ }^{45}$ Jurisprudence often stresses the positive aspects of this provision, which makes the register of Organizations similar to the General Role of judicial venues, although it has a non-innovative character, considering that Ministerial Decree No. 222 of 23 July 2004, that is rules for determination of criteria and modalities for registration as well as for keeping the register of mediation organizations outlined in Article 38 of Legislative Decree No. 58 of 17 January 2003, which was abrogated, contained a similar formulation.
} 
must create a real procedure file, because it is compulsory to keep a copy of the documents concerning the procedures for almost three years from the date of their conclusion.

This obligation is laid down by means of explicit reference to a law of the Civil Code, that is Article 1961 of the Civil Code, which exonerates registrars, arbitrators and lawyers from providing documents concerning disputes decided or ended over three years before the request $^{46}$.

Article 7 of Ministerial Decree No. 180 of 18 October 2010 provides for a further and precise duty on the part of the Organization towards the parties: keeping an appropriate file, which must be properly registered and numbered in the register of mediation matters, so that parties can have access to it at any moment if they need to examine or take out a copy of the documents deposited therein during joint sessions, or to their own documents deposited during a possible separate session decided by the mediator.

In connection with these data, the duty to protect confidential information therein contained seems almost natura ${ }^{47}$ [53]. It is an aspect to which the legislator has always attached great importance, considering that even the implementation decree points out the duty for all employees of the organization and for people involved in the mediation procedure to keep all information received during the mediation process confidential. This concerns both information about the parties and statements made by the parties during separate sessions [54].

In virtue of this duty, mediators benefit from special treatment: in case they are called to make statements before the legal authority or any other authority, they are not bound to give evidence on the statements made and information acquired during the mediation procedure.

\subsection{Carrying out the Procedure}

Through the submission of the application and the creation of the file, the procedure for the resolution of the dispute, with which the parties requested the mediator to deal, begins. Therefore obligations and guarantees arise and Organizations must guarantee them to the parties as a consequence of rules established by Organizations themselves, in accordance with laws and regulations in force.

The procedure outlined in Article 8 of Legislative Decree No. 28 of 4 March 2010 lays down fundamental and indispensable elements that each Organization must guarantee during the procedure and, as a consequence, to the parties involved in the procedure.

\footnotetext{
${ }^{46}$ The reference to Article 2961 of the Civil Code can be found in Article 12, 2nd paragraph, Ministerial Decree No. 180 of 18 October 2010.

47 "Collected data are used in accordance with provisions of Legislative Decree No. 196 of 30 June 2003, quoting "Code for the protection of personal data”.
}

The manager of the Organization, on submitting the application, must appoint the mediator and arrange the first meeting between the parties within fifteen days from the submission of the application.

Regulations do not explicitly state if the Organization is bound to communicate the mediation request to the party called to take part in the conciliation or if this obligation must be fulfilled by the applying party. What is certain is that the applying party is not burdened with notification obligation under the laws of the Code of Civil Procedure: the only obligation is that communication must be carried out "through every means which is appropriate to guarantee its receipt, also by the applying party [55]”.

At a literal level this seems to provide an indirect indication about the subject burdened with communication, that is the Organization, but it also provides for the possibility that the applying party might carry out communication. Certainly the choice of one of the two possibilities shall be clearly stated in the rules of procedure established by each Organization. As far as documents are concerned, as stated in the implementation decree, there are no particular formalities [56]. This choice on the part of the legislator seems to be based on the purposes of the procedure, which aims for a resolution of the dispute which implies reciprocal concessions to the counterparty, under the mediator's direction: therefore, the exclusion of formal obligations means avoiding procedural exceptions about the form of the documents burdening on dispute resolution.

After the first session in the presence of the parties and of the mediator, subsequent meetings can take place. An appropriate report shall be written about the meetings and kept, with the other documents, in the procedure file. However the legislator decided that the procedure must be completed within four months ${ }^{48}[57]$.

\section{Obligations of the Mediation Organization: Towards the Mediators}

The main relationship in mediation procedure is the relationship between parties and mediator.

This relationship can lead to the established goal of the procedure, which corresponds to writing a report which is appropriate in order to reconcile the different needs of the parties and has deflationary effect on the legal argument, if the regulation of a secondary relationship, as fundamental in average conciliation as the above-mentioned main relationship, occurs. The secondary relation-

\footnotetext{
${ }^{48}$ Great importance is attached to the specification, provided by subsequent article 7 of Legislative Decree No. 28 of 4 March 2010, that time necessary for mediation cannot be relevant for the calculation of the length of the process, because this stage constitutes a procedure, sometimes compulsory, which lies outside the jurisdictional phase of the dispute.
} 
ship is the relationship between mediation Organizations, to which parties apply for mediation, and mediators, who provide their service for these organizations.

\subsection{Registration}

This relationship is so important that, from the application onwards, it is regulated through obligations of the organization towards its mediators, as well as duties concerning mediators, which the organization must control.

Among obligations concerning the Organization, there is the duty to enclose the list of mediators who are willing to provide the mediation service for it, to the application for registration [58].

In virtue of this regulation, each Organization shall: 1) Make each mediator sign a statement of willingness to provide his/her service. This is also useful in order to check whether the limit of five organizations for which mediators can declare themselves willing to perform their functions is respected; 2) Get a concise CV of each mediator, with the qualification requisites provided for in Article 4, paragraph 3 of Ministerial Decree No. 180 of 18 October $2010^{49}$; 3) Get a certificate from mediators which proves the fulfilment of requirements of good repute outlined in Article 4, paragraph 3 of Ministerial Decree No. 180 of 18 October 2010; 4) Get documents which attest that mediators who want to be registered in the list of mediators who are expert in international matters have the necessary language skills.

The keeper of the register must check that mediators provide the above-mentioned written statements and that these ones correspond to reality. He/she must communicate any anomaly to the relevant bodies of the register in which mediators were entered, because violations can constitute criminal offences and can therefore be sanctioned as provided for in the respective ethical laws.

Besides these written statements, further obligations introduced by the legislative decree for implementation of average conciliation [59] are established for mediators.

First it is forbidden to assume rights and duties directly or indirectly linked with matters dealt with and to be paid directly by parties. The other obligations are: 1) To write a statement of impartiality for each dispute he/she is asked to resolve, using the words established in the rules of procedure; 2) To inform immediately the Organization and the parties about the reason why original impartiality has been compromised during mediation process.

As far as these obligations are concerned, the manager of the organization has the duty to control and he/she is empowered to provide for possible replacement of the mediator at the request of the party.

\footnotetext{
${ }^{49}$ On this aspect see 2.1 , where a description of the requirements that mediators must fulfill so that the Organizations can be registered is provided.
}

\subsection{Entrustment of Mediation Matters}

After the submission of the application for mediation to the secretariat of the Organization, this one must provide for the appointment of a mediator following the criteria that must have been introduced in the rules of procedure delivered to the Ministry of Justice ${ }^{50}$ [60].

This has two main goals: it allows the Organization to keep autonomy required by Law No. 69 of 18 June $2009^{51}$ and guarantees the professional expertise of mediators, so that the mediator's professional ability as suitable as possible for the nature of the dispute to resolve.

It is necessary that these criteria are explicitly stated and deal with the special technical knowledge provided by studies at university or by professional activities. On the basis of these criteria the Organization is expected to divide its mediators into categories and to establish the modalities to assign a dispute to a particular category of mediators.

Then the mediator shall receive a formal communication concerning the assignment of the dispute and shall write a statement of impartiality, on which depends the beginning of the mediation procedure ${ }^{52}$ [61] and without which the procedure cannot start.

For this reason, this written statement shall be included in the procedure file too and shall be at disposal of the parties for consultation.

Derogation from the criteria for the assignment of mediation matters is not possible unless the parties want it: rules can provide for the possibility of joint choice of the mediator for his/her appointment on the part of the Organization, as explicitly stated in Article 7 of Ministerial Decree No. 180 of 18 October 2010.

Replacement of the mediator can be requested also by a single party by means of a specific request to the Manager of the Organization, who shall provide for it [62].

A further guarantee of impartiality is provided by Article 15 of Ministerial Decree No. 180 of 18 October 2010, which forbids to Organizations to assume rights and duties linked with matters handled by mediators who provide service for themselves or for other organizations in accordance with collaboration agreements made.

\footnotetext{
${ }^{50}$ The rules of procedure shall include: "Mandatory criteria for the allocation of business mediation predetermined and respectful of the professional competence of the mediator appointed, also derived from the type of university degree held".

${ }^{51}$ Delegated law burdened the government with the drawing up of a regulation which provided for mediation service carried out by professsional and independent bodies, providing conciliation service steadily (Article 60, 3rd paragraph, letter b). The Circular of 20 December 2011 laid down by the General Director of Civil Justice offices, states that the provision for the predetermination of assignment criteria corresponds to a direct application of the principle.

52، The mediator is requested to: a) write, for each matter he is asked to deal with, a written statement of impartiality using words established by the rules of procedure, as well as further requirements provided for by the same rules".
} 


\subsection{Mediators' Duties}

The relationship between the Organization and its mediators is associated with a contract of intellectual professional service, according to which the mediator pledges himself/herself, for payment, to resolve the dispute arisen between the parties who turned to the Organization.

It is important to remark that parties are not allowed to have any direct relationship with the mediator, except during sessions held for dispute resolution. Moreover the mediator must not be directly paid by the parties [63].

Therefore the mediator binds himself/herself only towards the Organization by means of an obligation concerning means (and this is confirmed by the fact that the mediator is paid even in case of unsuccessful mediation) and provisions are laid down to establish the mediator's liability in case of incorrect conduct during the mediation process $^{53}$ [64].

Mediators are bound, of course, by the same duty of confidentiality as Organizations.

Whoever (mediators, secretaries, collaborators) provides his/her service in the organization or during the mediation process has a specific duty of confidentiality imposed by Article 9 of Legislative Decree No. 28 of 4 March 2010. The mediator cannot use statements made or information acquired during the mediation process to avail himself/herself of it or to testify in favour of other people in other proceedings concerning the same subject or in court proceedings following unsuccessful mediation, unless explicitly authorized by the party in question.

Besides these obligations, duties linked to the function as mediator in the dispute are described in Article 11 of Legislative Decree No. 28 of 4 March 2010. At the end of the mediation process the mediator has the duty of writing a report which certifies that an out-of-court agreement has been reached or he/she shall draw up a proposal in case of failure to reach an agreement or of joint request of the parties. The only limitation to the activity of the mediator is the respect of law and order and mandatory rules. However the only means of checking the respect of this limitation is the subsequent judgment of suitability on the part of the President of the court, which is provided only at the request of the party. For this reason someone pointed out the chance of consulting the Manager of the Organization or a lawyer in order to examine the proposal that will be delivered to the secretariat of the Organization.

The Organization is held responsible if the party, on implementing the proposal, cannot reach a recognition of validity because of a conflict between the report and mandatory rules or law and order.

\footnotetext{
${ }^{53}$ Some of the possible cases in which the mediator is held responsible are: failure to inform the Manager of the Organization in case of disputes which require specific technical competences and, in particular, the mediator's behavior during the sessions with the parties.
}

In all cases the mediator shall sign the text prepared and ensure that the parties which accept it and enclose it to the report, also sign it.

If no agreement is reached, the mediator shall write a negative report, indicating his/her proposal and any failure to participate in the procedure by one of the parties as well as getting the present parties to sign it.

After getting the signature of the parties on the report, the mediator shall deliver it to the secretariat of the Organization, which provides a copy of the document to parties which require it.

Article 8 of Ministerial Decree No. 180 of 18 October 2010 states that the Manager of the Organization shall provide a copy of the report to parties if they want to request its validation.

\section{REFERENCES}

[1] G. Dosi, "La Mediazione Civile Come Condizione Di Procedibilità Della Domanda Giudiziale (Ma Non Più Nel Rito Del Lavoro)," Famiglia Persone e Successioni, Vol. 5, No. 5, 2011, pp. 327-345.

[2] I. Lombardini, “Considerazioni Sulla Legge Delega in Materia Di Mediazione e Conciliazione Nelle Controversie Civili e Commerciali,” Studium Iuris, Vol. 1, 2010, pp. 8-16.

[3] F. P. Luiso, "La Delega in Materia Di Mediazione e Conciliazione,” Rivista di Diritto Processuale, Vol. 5, 2009, pp. 1257-1265.

[4] Legislative Decree No. 28 of 4 March 2010, Article 16, 1st paragraph.

[5] Legislative Decree No. 28 of 4 March 2010, Article 16, 4th paragraph.

[6] Legislative Decree No. 28 of 4 March 2010, Article 16, 3rd paragraph.

[7] Legislative Decree No. 28 of 4 March 2010, Article 18.

[8] Legislative Decree No. 28 of 4 March 2010, Article 19.

[9] Ministerial Decree No. 180 of 18 October 2010, Article 3, 3rd paragraph.

[10] I. Ambrosi and M. D’Auria, "La Mediazione: Circolare Interpretativa Sui Criteri e Sulle Modalità Di Iscrizione e Tenuta Del Registro Degli Organismi Di Mediazione Nonché in Materia Di Indennità Per il Compimento Del Servizio Di Mediazione e Conciliazione,” Famiglia, Persone e Successioni, Vol. 2, 2012, pp. 157-158.

[11] Circular of 20 December 2011.

[12] Ministerial Decree No. 180 of 18 October 2010, Article 7.

[13] M. Gorga, “Mediazione e Formazione,” Scriptaweb, 2010.

[14] A. Contaldo and M. Gorga, "La Mediazione Civile e Commerciale Alla Luce Del d.m. 180 Del 4 Novembre 2010,” Corriere Giuridico, Vol. 2, 2011, pp. 5-34.

[15] L. Ansaldi, "Le Recenti Novità Legislative in Materia Di Mediazione,” Contratti, Vol. 2, 2012, pp. 207-211.

[16] Article 2 of Ministerial Decree No. 145 of 6 July 2011. 
[17] F. C. Ulloa, “Decreto Legislativo 4 Marzo 2010, No. 28 Attuazione Dell'Articolo 60 Della Legge 18 Giugno 2009, No. 69, in Materia Di Mediazione Finalizzata Alla Conciliazione Delle Controversie Civili e Commerciali,” Giuffrè, 2010.

[18] Article 4, 3rd paragraph, Ministerial Decree No. 180 of 18 October 2010.

[19] Article 16, 3rd paragraph, Ministerial Decree No. 180 of 18 October 2010.

[20] Article 14, 2nd paragraph, letter a) of Legislative Decree No. 28 of 4 March 2010.

[21] Article 7, 3rd paragraph, letter d), Ministerial Decree No. 180 of 18 October 2010.

[22] Circular of 4 April 2011, General Director of Civil Justice.

[23] Article 7, 3rd paragraph, letter e), Ministerial Decree No. 180 of 18 October 2010.

[24] Article 9, 2nd paragraph, Legislative Decree No. 28 of 4 March 2010.

[25] Article 7, 5th paragraph, letter b), Ministerial Decree No. 180 of 18 October 2010.

[26] Article 1, letter h), Ministerial Decree No. 180 of 18 October 2010.

[27] Article 5, 1st paragraph, Ministerial Decree No. 180 of 18 October 2010.

[28] Article 16, 3rd paragraph, Legislative Decree No. 28 of 4 March 2010.

[29] Article 17, Legislative Decree No. 28 of 4 March 2010.

[30] Article 11, Legislative Decree No. 28 of 4 March 2010.

[31] Article 5, letter b), Ministerial Decree No. 145 of 6 July 2011.

[32] Ministerial Circular of 20 December 2011.

[33] Article 16, 10th paragraph, Ministerial Decree No. 180 of 18 October 2010.

[34] Article 16, 14th paragraph, Ministerial Decree No. 180 of 18 October 2010.

[35] A. Castagnola and F. Delfini, "La Mediazione Nelle Controversie Civili e Commerciali," Cedam.

[36] Article 5, 1st paragraph, letter d), Ministerial Decree No. 145 of 6 April 2011.

[37] Article 9, 2nd paragraph, Ministerial Decree No. 180 of 18 October 2010.

[38] Article 76, Decree of the President of the Republic No.
115 of 30 May 2002.

[39] Article 2, 1st paragraph, Law No. 249 of 7 August 1990.

[40] Article 21, Law No. 241 of 7 August 1990.

[41] Article 9, Ministerial Decree No. 180 of 18 October 2010.

[42] Article 8, 1st paragraph and Article 20 of Ministerial Decree No. 180 of 18 October 2010.

[43] Articles 17 and 20, Legislative Decree No. 28 of 4 March 2010.

[44] Article 7, 3rd paragraph, Ministerial Decree No. 180 of 18 October 2010

[45] Article 10, 3rd paragraph, Ministerial Decree No. 180 of 18 October 2010.

[46] Article 12, Legislative Decree No. 28 of 4 March 2010.

[47] Article 5, Legislative Decree No. 28 of 4 March 2010.

[48] Article 4, Legislative Decree No. 28 of 4 March 2010.

[49] Article 8, 2nd paragraph. Legislative Decree No. 28 of 4 March 2010.

[50] Article 4, Legislative Decree No. 28 of 4 March 2010.

[51] G. Buffone, “Mediazione e Conciliazione,” Giuffré, 2010.

[52] Article 12, Ministerial Decree No. 180 of 18 October 2010.

[53] Article 7, 8th paragraph, Ministerial Decree No. 180 of 18 October 2010

[54] Article 9, Legislative Decree No. 28 of 4 March 2010.

[55] Article 8, Legislative Decree No. 28 of 4 March 2010.

[56] Article 3, Legislative Decree No. 28 of 4 March 2010.

[57] Article 6, Legislative Decree No. 28 of 4 March 2010.

[58] Article 6, Ministerial Decree No. 180 of 18 October 2010.

[59] Article 14, Legislative Decree No. 28 of 4 March 2010.

[60] Article 7, 3rd paragraph, letter e), Ministerial Decree No. 180 of 18 October 2010

[61] Article 14, 2nd paragraph, letter a), Legislative Decree No. 28 of 4 March 2010.

[62] Article 14, 3rd paragraph, Legislative Decree No. 28 of 4 March 2010.

[63] Article 14, 1st paragraph, Legislative Decree No. 28 of 4 March 2010

[64] S. Tommasi, "Brevi Riflessioni Sulle Responsabilità Del Mediatore Nella Mediazione Civile,” Il Fisco, Vol. 45, 2011, pp. 7333-7348. 